\title{
Airway function in adults with mild-to-moderate scoliosis treated in adolescence with specific physical exercises. An ongoing, case-control study
}

\author{
M Plaszewski ${ }^{*}$, R Nowobilski $^{2}$, P Kowalski ${ }^{3}$, Jerech $^{4}$, M Cieslinski $^{1}$, I Cieslinski ${ }^{1}$ \\ From 8th International Conference on Conservative Management of Spinal Deformities and SOSORT 2011 \\ Annual Meeting \\ Barcelona, Spain. 19-21 May 2011
}

\section{Background}

Scoliosis can lead to a decrease in total lung capacity (TLC) and alterations in maximal flow - volume curves, associated with structural deformities and curve magnitude, but also with chronicity of the problem and respiratory muscle inefficiency [1-4]. However, evidence confirming the assumption of beneficial, long lasting influence of scoliosis specific exercise on respiratory function is lacking.

\section{Purpose}

We aimed to analyze respiratory function in adults with history of participation in a scoliosis - specific exercise program, in comparison to normative values and to agematched subjects, with reference to confounders: smoking and physical activity.

\section{Materials and methods}

Maximal flow-volume curves, ventilatory parameters (vital capacity - VC, forced $\mathrm{VC}$ in exertion and in insertion = FVCin and FVCex) and TLC values were analyzed in 25 adults ( 22 females), who attended in adolescence (from 1984 to 1995, at initial age of 11 - 13) the Centre of Corrective and Compensatory Gymnastics, BielskoBiala, Poland. The WHO General Physical Activity Questionnaire was also completed. The non-parametric rang Kruskal-Wallis ANOVA was performed among subgroups with moderate and mild scoliosis $\left(>40^{\circ} \mathrm{Cobb}\right.$, $\mathrm{n}=3 ; 25-39^{\circ}, \mathrm{n}=2 ; 10-24^{\circ}, \mathrm{n}=20$, respectively) and compared to 17 age-matched normal controls (11 females).

'University School of Physical Education, Warsaw, Poland, Faculty of Physical Education in Biala Podlaska, Poland

Full list of author information is available at the end of the article

\section{Results}

Generally, scoliotic subjects did not differ significantly from controls and normal values. However, FVCin was below normal values $\left(x=86.4 \%\right.$ in $\left.10-24^{\circ} \mathrm{Cobb}\right), \mathrm{VC}$ and TLC means differed nonsignificantly $(\mathrm{p}=.070$ and $\mathrm{p}=.074$, respectively).

\section{Conclusion}

In general, the results suggest satisfactory lung functioning, but FVCin analysis indicates inspiratory inefficiency, regardless severity of the deformation.

\section{Acknowledgements}

This paper is a part of a research project DS.136, University School of Physical Education, Warsaw, Poland.

\section{Author details}

${ }^{1}$ University School of Physical Education, Warsaw, Poland, Faculty of Physical Education in Biala Podlaska, Poland. ${ }^{2}$ Department of Medicine, Jagiellonian University School of Medicine, Cracow, Poland. ${ }^{3}$ Higher School of Administration, Bielsko-Biala, Poland. ${ }^{4}$ Complex Hospital for Tuberculosis and Pulmonary Diseases, Bystra Slaska, Poland.

\section{Published: 27 January 2012}

\section{References}

1. Asher MA, Burton DA: Adolescent idiopathic scoliosis: natural history and long term treatment effects. Scoliosis 2006, 1:2.

2. Barrios C, Pérez-Encinas C, Maruenda Jl, Laguía M: Significant ventilatory functional restriction in adolescents with mild or moderate scoliosis during maximal exercise tolerance test. Spine 2005, 30:1610-5.

3. Koumbourlis AC: Scoliosis and the respiratory system. Paediatr Respir Rev 2006, 7:152-160.

4. Trobisch P, Suess O, Schwab F: Idiopathic scoliosis. Dtsch Arztebl Int 2010, 107:875-883

\section{doi:10.1186/1748-7161-7-S1-055}

Cite this article as: Plaszewski et al:: Airway function in adults with mildto-moderate scoliosis treated in adolescence with specific physical exercises. An ongoing, case-control study. Scoliosis 2012 7(Suppl 1):055. 